\title{
ENRAIZAMENTO DE ESTACAS DE Trichilia catigua A. Juss (CATIGUA) EM DIFERENTES ESTAÇÕES DO ANO ${ }^{1}$
}

Janice Valmorbida $^{2}$, Carmen Sílvia Fernandes Boaro ${ }^{3}$, Antonio Oliveira Lessa ${ }^{4}$, Airton Rodrigues Salerno ${ }^{5}$

\begin{abstract}
RESUMO - Pertencente à família Meliaceae, Trichilia catigua A. Juss possui casca com propriedades adstringente, inseticida, purgativa, tônica, bactericida, antiinflamatória e antidepressiva. Este estudo objetivou enraizar estacas de ramos lenhosos da espécie em diferentes estações do ano. Para tal, estacas com aproximadamente $15 \mathrm{~cm}$ de comprimento, coletadas de árvores adultas, foram preparadas da parte apical e mediana dos ramos e submetidas aos reguladores vegetais AIB (ácido indolbutírico), ANA (ácido naftalenoacético) e AIA (ácido 3 indolacético). Determinaram-se a porcentagem de estacas enraizadas e mortas e, quando enraizadas, seu comprimento e diâmetro. Na primavera de 2004, as estacas foram submetidas às concentrações de 1.000 e $2.000 \mathrm{mg} \mathrm{L}^{-1} \mathrm{de}$ AIB, ANA e AIA e avaliadas aos 90 dias. As maiores porcentagens de enraizamento foram iguais a 33,33; 25,00; 22,91; e 23,43\%, respectivamente com AIB 1.000, $2.000 \mathrm{mg} \mathrm{L}^{-1}$ e ANA 1.000 e $2.000 \mathrm{mg} \mathrm{L}^{-1}$. No verão, outono, inverno e primavera de 2005 os experimentos foram conduzidos com AIB, ANA e AIA nas concentrações de $1.000,2.000 \mathrm{e} 3.000 \mathrm{mg} \mathrm{L}^{-1}$, sendo as avaliações realizadas aos 120 dias. A maior porcentagem de enraizamento, igual a 19,17\%, foi obtida com AIB $3.000 \mathrm{mg} \mathrm{L}^{-1}$. Na primavera de 2006 foram testadas as doses iguais a 1.000, $2.000,3.000,4.000$ e $5.000 \mathrm{mg} \mathrm{L}^{-1}$ de AIB e $1.000,2.000$ e $3.000 \mathrm{mg} \mathrm{L}^{-1}$ de ANA. A maior porcentagem de enraizamento, 41,67\%, foi obtida com a utilização de $5.000 \mathrm{mg} \mathrm{L}^{-1}$ de AIB.
\end{abstract}

Palavras-chave: Ácido indolbutírico, planta medicinal e estaca lenhosa.

\section{ROOTING OF Trichilia catigua A. Juss (CATIGUA) STEM CUTTINGS IN DIFFERENT SEASONS OF THE YEAR}

\begin{abstract}
Trichilia catigua A. Juss contains substances with astringent, insecticidal, purgative, tonic, bactericidal, anti-inflammatory and anti-depressive properties in its barks. This study aimed at rooting of hardwood cuttings of this species in different seasons. Stem cuttings-about $15 \mathrm{~cm}$ long-were collected from adult trees and were prepared from the apical and medial part of the branches. The cuttings were treated with the plant regulators AIB (indole-3-butyric acid), NAA (naphthalene acetic acid) and IAA (indole3-acetic acid). The percentage of rooted or dead stem cuttings was determined; when rooting was successful, length and diameter were measured. In the spring of 2004 stem cuttings were treated with concentrations of 1000 and $2000 \mathrm{mg} \mathrm{L}^{-1}$ of IBA, NAA and IAA and evaluated after 90 days. The greatest rooting percentages were 33.33, 25.00, 22.91 and 23.43\% with IBA 1000, $2000 \mathrm{mg} \mathrm{L}^{-1}$ and NAA 1000 and $2000 \mathrm{mg} \mathrm{L}^{-1}$, respectively. In the summer, fall, winter and spring of 2005 the experiments were carried out with IBA, NAA and IAA in the concentrations of 1000, 2000 and $3000 \mathrm{mg} \mathrm{L}^{-1}$ and the evaluations done at 120 days. The higher rooting percentage, $19.17 \%$, was obtained with IBA at $3000 \mathrm{mg} \mathrm{L}^{-1}$. In the spring of 2006 IBA at doses 1000, 2000, 3000, 4000 and $5000 \mathrm{mg} \mathrm{L}^{-1}$, and NAA at 1000, 2000 and $3000 \mathrm{mg} \mathrm{L}^{-1}$ were tested. The greatest rooting percentage was $41.67 \%$, and was obtained with the use of $5000 \mathrm{mg} \mathrm{L}^{-1}$ of AIB.
\end{abstract}

Keywords:Indole-3-butyric acid, medicinal plant and wood cutting.

\footnotetext{
${ }^{1}$ Recebido em 08.06.2007 e aceito para publicação em 19.05.2008.

${ }^{2}$ Escola Agrotécnica Federal de Rio do Sul, EAFRS, Friburgo-RS. E-mail: <jvalmorbida@yahoo.com.br>.

${ }^{3}$ Departamento de Botânica da Universidade Estadual Paulista Júlio de Mesquita Filho(UNESP), Botucatu-SP. E-mail: <csfboaro@ibb.unesp.br>.

${ }^{4}$ Empresa de Pesquisa Agropecuária e Extensão Rural de Santa Catarina S.A., Epagri, Lages-SC.

${ }^{5}$ Empresa de Pesquisa Agropecuária e Extensão Rural de Santa Catarina S.A., Epagri, Itajaí-SC.
} 


\section{INTRODUÇÃO}

Pertencente a família Meliaceae, a espécieT. catigua A. Juss. é popularmente conhecida como catigua, catiguá, cataguá, angelim-rosa, mangalto-catinga (KLEIN, 1984). É encontrada desde o Rio Grande do Sul até Minas Gerais, ocorrendo preferencialmente nas matas ciliares e mesófilas do interior (PASTORE, 2003). A caracterização farmacognóstica das cascas de $T$. catigua mostrou a presença de flavonóides, antracênicos livres, taninos condensados e saponinas, bem como a ausência de alcalóides, mucilagens, cumarinas e óleos essenciais (OLIVEIRA et al., 2003). Catigua é encontrada no fitoterápico Catuama ${ }^{\circledR}$, comercializado no Brasil como tônico, estimulante e afrodisíaco. Fazem parte também da sua composição, Paullinia cupana (guaraná), Ptychopetalum olacoides (muirapuama) e Zingiber officinale (gengibre) (FAPESP, 2002; MENDES e CARLINI, 2007).

Por se tratar de uma planta cujos princípios ativos são encontrados na casca e, por haver uma demanda pela matéria-prima, foi considerada como espécie prioritária de conservação e manejo (VIEIRA e SILVA, 2002). Mesmo assim, são raros os estudos encontrados sobre a espécie e os efeitos provocados pelo extrativismo. Aliado a isso, as áreas de ocorrência, principalmente em Santa Catarina e no Paraná, são de atividades agropecuárias, aumentando a necessidade da elaboração de protocolos de propagação, com vistas à recomposição das matas e possibilidade de realização de cultivos comerciais.

As auxinas têm sido utilizadas como promotores de enraizamento em espécies frutíferas, florestais, ornamentais e medicinais, em ramos herbáceos ou lenhosos. Sua aplicação na base das estacas promove o enraizamento, dependendo da concentração, que diferindo em cada espécie pode, inclusive, apresentar efeito inibitório ou fitotóxico (HARTMANN et al., 2002; FACHINELLO et al., 2005). Segundo Fachinello et al. (2005), o uso de reguladores vegetais pode ser decisivo para a formação de raízes nas estacas e tem por finalidade aumentar a porcentagem de estacas enraizadas, acelerar sua iniciação e aumentar o número e qualidade das raízes formadas, com maior uniformidade de enraizamento.

É importante ainda relacionar a estação do ano com as fases de desenvolvimento das plantas, visto que o estado bioquímico das estacas tem grande influência no enraizamento (HARTMANN et al., 2002;
FACHINELLO et al., 2005). Para determinar a melhor época de coleta, Dutra et al. (2002) utilizaram estacas de pessegueiro, Prunus persica (L.), submetidas a várias concentrações de AIB, nas quatro estações do ano, e os resultados indicaram os maiores porcentuais de enraizamento na primavera e no verão.

O objetivo deste estudo foi enraizar estacas de ramos lenhosos de Trichilia catigua A. Juss, nas quatro estações do ano, utilizando as auxinas ácido indolbutírico (AIB), ácido naftalenoacético (ANA) e ácido 3indolacético (AIA), em diferentes dosagens.

\section{MATERIAL E MÉTODOS}

O estudo foi desenvolvido com a instalação de três experimentos, realizados na Estação Experimental da Empresa de Pesquisa Agropecuária e Extensão Rural de Santa Catarina - Epagri, localizada no Município de Lages, no Estado de Santa Catarina.

O material vegetativo foi coletado em matas localizadas no extremo-oeste catarinense, nas cidades de São Miguel do Oeste e Paraíso. Para tanto, foram retirados ramos lenhosos com folhas de árvores adultas, com boa sanidade, sem florescimento ou frutificação. No local da coleta, os ramos foram separados em estacas apical e mediana, desprezando-se a parte basal por, na maioria das vezes, não apresentar folhas. Para adequada manutenção das condições das estacas, as partes foram umedecidas, acondicionadas em caixas de isopor e transportadas para o local de realização dos experimentos.

Nas dependências da Epagri, as estacas foram desfolhadas, mantendo-se apenas duas folhas. Estacas de comprimento aproximado de $15 \mathrm{~cm}$ foram preparadas, sendo realizadas com estilete duas lesões de aproximadamente $2 \mathrm{~cm}$, na base, expondo-se o câmbio.

Os tratamentos consistiram do uso de água destilada como testemunha e das auxinas AIB, ANA e AIA, todos produtos P.A. marca Vetec $®$. Mergulhou-se a base das estacas por $10 \mathrm{~s}$ em água destilada e nas soluções de auxinas. Durante o período de avaliação, mantiveramse as estacas em túnel de aclimatização, sem controle de temperatura, com nebulização intermitente de 1 min a cada hora.

Foram realizados três experimentos. O primeiro experimento, instalado em setembro de 2004, objetivou a obtenção de dados iniciais a respeito da propagação 
da espécie. Para tal, estacas apicais e medianas foram submetidas aos tratamentos com reguladores vegetais AIB (1.000 e $2.000 \mathrm{mg} \mathrm{L}^{-1}$ ), ANA (1.000 e $2.000 \mathrm{mg} \mathrm{L}^{-1}$ ), AIA ( 1.000 e $2.000 \mathrm{mg} \mathrm{L}^{-1}$ ) e com água destilada (testemunha). Depois do preparo, as estacas foram plantadas em bandejas pretas contendo areia grossa lavada, como substrato. O delineamento experimental adotado foi em blocos casualizados em esquema fatorial $7 \times 2$, ou seja, sete tratamentos e duas posições da retirada da estaca dos ramos (mediana e apical), com quatro repetições. Devido à baixa disponibilidade de material vegetativo, as parcelas contendo estacas da posição apical foram constituídas por seis estacas e da posição mediana, por oito. Aos 90 dias da instalação do experimento foram avaliadas as porcentagens de estacas enraizadas e mortas e, quando enraizadas, o comprimento e diâmetro das raízes.

No segundo experimento, foi testado o enraizamento de estacas coletadas nas estações verão 2004/2005, outono, inverno e primavera de 2005 . Em cada estação, estacas apicais e medianas foram submetidas aos tratamentos com reguladores vegetais $\mathrm{AIB}(1.000,2.000$ e $\left.3.000 \mathrm{mg} \mathrm{L}^{-1}\right)$, ANA $\left(1.000,2.000\right.$ e $\left.3.000 \mathrm{mg} \mathrm{L}^{-1}\right) \mathrm{e}$ AIA (1.000, 2.000 e $3.000 \mathrm{mg} \mathrm{L}^{-1}$ ) e com água destilada (testemunha). Após o preparo, as estacas foram plantadas em bandejas de poliestireno expandido com 72 células, contendo areia grossa lavada. O delineamento experimental adotado foi em blocos casualizados em esquema fatorial $10 \times 2 \times 4$, sendo 10 tratamentos, duas posições da retirada da estaca dos ramos (mediana e apical) e quatro estações de coleta, com cinco repetições. Cada parcela foi constituída de seis estacas. Aos 120 dias da instalação do experimento, avaliaram as porcentagens de estacas enraizadas e mortas e o comprimento e diâmetro das raízes.

Os resultados dos experimentos 1 e 2 evidenciaram a necessidade de realização do experimento 3 , com o objetivo de avaliar concentrações mais elevadas de reguladores vegetais, especialmente do AIB, sendo realizado na primavera de 2006. Estacas da posição mediana foram submetidas aos tratamentos com AIB (1.000, 2.000, 3.000, 4.000 e $5.000 \mathrm{mg} \mathrm{L}^{-1}$ ), ANA (1.000, 2.000 e $3.000 \mathrm{mg} \mathrm{L}^{-1}$ ) e com água destilada (testemunha). O delineamento experimental utilizado foi em blocos casualizados com nove tratamentos e quatro repetições, sendo seis estacas por parcela. Aos 120 dias da instalação do experimento foram avaliadas as porcentagens de estacas enraizadas e mortas e o comprimento e diâmetro das raízes.
Os dados de porcentagens de plantas enraizadas, não-enraizadas e mortas foram analisados por regressão logística (KAPS e LAMBERSON, 2004) e o comprimento e diâmetro das raízes submetidos à análise de variância, utilizando-se o pacote estatístico SAS (SAS INSTITUTE, 1998). Para comprimento e diâmetro das raízes, os dados foram previamente testados para normalidade dos resíduos pelo teste de Shapiro-Wilk (SANTANA e RANAL, 2004), sendo realizada a transformação logarítmica, quando necessário. Na análise dos dados da primavera e verão, estações em que ocorreu o enraizamento no experimento 2 , os dados foram testados para homogeneidade de variâncias pelo teste de Levene (KAPS e LAMBERSON, 2004). Em todos os experimentos foram analisados os efeitos dos fatores principais (tratamento, estação do ano e posição de retirada da estaca do ramo, conforme o caso) e das interações entre eles.

\section{RESULTADOS E DISCUSSÃO}

A porcentagem de estacas enraizadas, de acordo com os diferentes tratamentos, nos três experimentos, pode ser observada na Tabela 1 .

O enraizamento no tratamento-testemunha em todos os experimentos pode estar relacionado ao nível endógeno de auxina nas estacas (Tabela 1). Devido às baixas percentagens de enraizamento nessas condições, fazse necessário o uso de auxinas exógenas para a espécie. Muitas espécies enraízam sem a necessidade de reguladores vegetais. Outras necessitam de baixas concentrações de reguladores durante maiores tempos de exposição ao tratamento, como estacas semilenhosas de cafeeiro (Coffea arabica) que necessitaram de 100 e $200 \mathrm{mg} \mathrm{L}^{-1}$ de ANA mais boro, em imersão por $24 \mathrm{~h}$, para melhores taxas de enraizamento (ONO et al., 1992). No entanto, mesmo submetidas a reguladores vegetais, estacas de muitas plantas não enraízam, como no caso das de bolsa-de-pastor (Zeyheria montana Mart.) submetidas às auxinas AIB, ANA e AIA, nas concentrações iguais a 25, 50, 100 e $150 \mathrm{mg} \mathrm{L}^{-1}$ e diferentes substratos (CARDOSO et al., 2002).

Nos experimentos 1 e 2 (Tabela 1), a aplicação de AIA exógeno resultou em baixas porcentagens de estacas enraizadas, motivo pelo qual o regulador não foi usado no experimento 3. A auxina AIA, menos estável do que AIB e ANA, é fotossensível, sujeito à decomposição pela enzima AIA-oxidase (FACHINELLO et al., 2005).

R. Árvore, Viçosa-MG, v.32, n.3, p.435-442, 2008 
Quadro 1 - Porcentagem de estacas enraizadas de Trichilia catigua A. Juss de acordo com os tratamentos (auxinas aplicadas em diferentes concentrações), a estação de coleta e a parte do ramo, nos experimentos 1 (primavera de 2004), 2 (verão de 2004-2005/primavera de 2005) e 3 (primavera de 2006) ${ }^{1}$

Table 1 - Percentage of rooted cuttings of Trichilia catigua A. Juss according to treatments (auxins applied in different concentrations), collection season and part of the branches in the experiments: 1 (spring 2004), 2 (summer 2004/spring 2005) and 3 (spring 2006) ${ }^{I}$

\begin{tabular}{|c|c|c|c|}
\hline \multirow[t]{2}{*}{ Variável } & \multicolumn{3}{|c|}{ Estacas Enraizadas (\%) } \\
\hline & Experimento 1 & Experimento 2 & Experimento 3 \\
\hline \multicolumn{4}{|c|}{ Tratamento $\left(\mathrm{mg} \mathrm{L}^{-1}\right)$} \\
\hline AIA 1.000 & $7,29 \quad b$ & $3,33 \quad \mathrm{c}$ & - \\
\hline AIA 2.000 & $10,41 \mathrm{~b}$ & $5,83 \mathrm{bc}$ & - \\
\hline AIA 3.000 & - & $10,00 \mathrm{~b}$ & - \\
\hline ANA 1.000 & $22,91 \mathrm{ab}$ & 5,83 bc & $8,33 \mathrm{~b}$ \\
\hline ANA 2.000 & 23,43 a & $14,17 \mathrm{ab}$ & $29,17 \mathrm{ab}$ \\
\hline ANA 3.000 & & $14,17 \mathrm{ab}$ & $16,67 \mathrm{~b}$ \\
\hline AIB 1.000 & 33,33 a & $11,67 \mathrm{~b}$ & $12,50 \mathrm{~b}$ \\
\hline AIB 2.000 & $25,00 \mathrm{a}$ & $15,83 \mathrm{ab}$ & $12,50 \mathrm{~b}$ \\
\hline AIB 3.000 & - & 19,17 a & $16,67 \mathrm{~b}$ \\
\hline AIB 4.000 & - & - & $25,00 \mathrm{ab}$ \\
\hline AIB 5.000 & - & - & $41,67 \mathrm{a}$ \\
\hline Testemunha & $7,81 \quad b$ & $4,17 \quad \mathrm{bc}$ & $12,50 \mathrm{~b}$ \\
\hline \multicolumn{4}{|l|}{ Estação $^{2}$} \\
\hline Primavera de 2005 & - & $14,67 \mathrm{a}$ & - \\
\hline Verão de $2004 / 2005$ & - & $6,17 \mathrm{~b}$ & - \\
\hline \multicolumn{4}{|l|}{ Partes do ramo ${ }^{3}$} \\
\hline Apical & $16,67 \mathrm{a}$ & $10,50 \mathrm{a}$ & - \\
\hline Mediana & $20,54 \mathrm{a}$ & $10,33 \mathrm{a}$ & - \\
\hline
\end{tabular}

${ }^{1}$ Médias seguidas da mesma letra dentro de cada variável, na coluna, não diferem entre si, por regressão logística a 5\%.

2 Variável testada somente no experimento 2.

${ }^{3}$ Variável testada nos experimentos 1 e 2.

O enraizamento das estacas originadas da parte mediana não diferiu daquele da parte apical nos experimentos 1 e 2 , sendo, dessa forma, utilizado no experimento 3 somente estacas da parte mediana (Tabela 1).

Nas estações outono e inverno de 2005, experimento 2 , não houve enraizamento das estacas coletadas, não sendo observada morte e tampouco queda das folhas das estacas. Nesse período, as baixas temperaturas, tanto no local de coleta quando no de enraizamento, podem ter influenciado, impedindo o enraizamento. Para Xavier et al. (2003), temperaturas baixas, em torno de $16^{\circ} \mathrm{C}$, proporcionam condições fisiológicas menos favoráveis às plantas, diminuindo, com isso, o enraizamento. Isso ocorreu no enraizamento de miniestacas de cedro-rosa (Cedrela fissilis Vell.).
No experimento 2, observou-se que a porcentagem de enraizamento foi significativamente superior na primavera em relação ao verão. Contudo, maior porcentagem de estacas mortas foi verificada na primavera de 2005 (Tabela 1). Fachinello et al. (2005) realizaram coletas na primavera/verão e observaram crescimento vegetativo mais intenso do que no outono/ inverno, que atribuíram isso ao fato de as estacas serem mais herbáceas na primavera/verão, portanto tendem a enraizar mais. Já as estacas coletadas no inverno tendem a ser mais lignificadas e possuem menor capacidade de enraizamento.

No experimento 2, observou-se porcentagem mais elevada de estacas enraizadas na dose de AIB igual a $3.000 \mathrm{mg} \mathrm{L}^{-1}$ (Tabela 1). Contudo, os resultados do experimento 3 indicaram que concentrações mais elevadas de AIB na primavera podem, no entanto, 
resultar em porcentagens de enraizamento significativamente superiores. Nesse experimento, o AIB na concentração de $5000 \mathrm{mg} \mathrm{L}^{-1}$ resultou nas maiores porcentagens de estacas enraizadas $(41,67 \%)$, não diferindo de AIB $4.000 \mathrm{mg} \mathrm{L}^{-1}$ e ANA $2.000 \mathrm{mg} \mathrm{L}^{-1}$. $\mathrm{O}$ aumento das porcentagens de enraizamento com o aumento das concentrações de AIB (Figura 1) indica que concentrações acima de $5.000 \mathrm{mg} \mathrm{L}^{-1}$ do regulador vegetal AIB podem resultar em melhores porcentagens de estacas enraizadas.

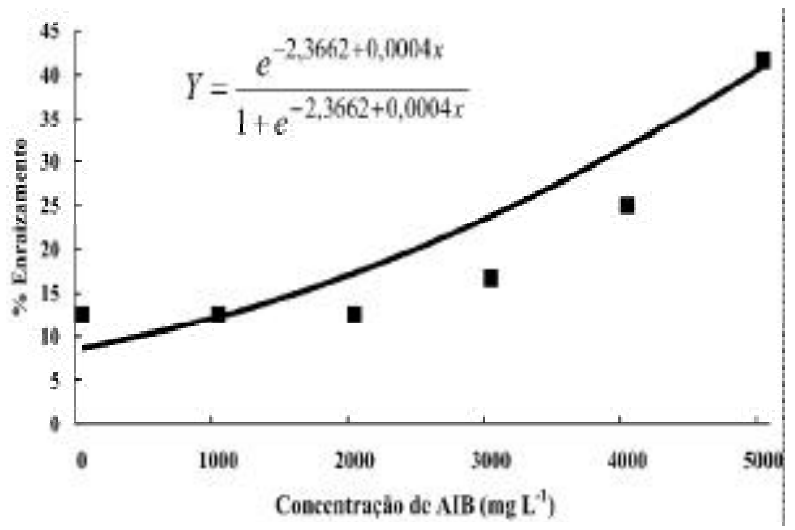

Figura 1 - Porcentagem de estacas de Trichilia catigua A. Juss enraizadas na primavera de 2006, em função das concentrações de AIB utilizadas. Equação estimada por regressão logística (P $<0,01)$.

Figure 1 - Percentage of Trichilia catigua A. Juss. stem cuttings rooted in the spring of 2006, as a function of the used AIB concentrations. Equation estimated by logistic regression $(P<0,01)$.

Muitos trabalhos têm testado o uso de diferentes concentrações de reguladores vegetais para promover melhor enraizamento. Paes et al. (2003), usando AIB e ANA em estacas de Kiwizeiro (Actinidia deliciosa) nas concentrações de $0,2.500$ e $5.000 \mathrm{mg} \mathrm{L}^{-1}$, em solução e em talco, verificaram $70 \%$ de estacas enraizadas quando submetidas a $5.000 \mathrm{mg} \mathrm{L}^{-1}$ de ANA em talco, no inverno. Mindêllo Neto et al. (2004) testaram tratamentos com AIB constituídos por 0, 100, 500, 1.000 e $5.000 \mathrm{mg} \mathrm{L}^{-1} \mathrm{em}$ estacas lenhosas de pessegueiro, cultivar Marfim. Observaram 81,92\% de estacas enraizadas na concentração de $2.966 \mathrm{mg} \mathrm{L}^{-1}$ de AIB, com redução de enraizamento em doses superiores. Oliveira et al. (2006) obtiveram, em plantios comerciais de Eucalyptus sp, mudas clonadas, utilizando-se 4.000 mg L ${ }^{-1}$ de AIB.
A porcentagem de estacas mortas, no experimento 1 (Tabela 2), foi mais baixa em relação aos mesmos tratamentos nos demais experimentos. Esse resultado pode estar relacionado ao fato de que, no ano de 2004, foram registradas temperaturas amenas, com máxima de $23,1^{\circ} \mathrm{C}$ no período e ocorrência normal de chuvas. Em 2005 e 2006, as temperaturas máximas registradas foram de 26,9 e $25,8^{\circ} \mathrm{C}$, respectivamente, com ocorrência de longa estiagem em 2005. Observações realizadas na mata permitiram constatar que, em anos de pouca chuva e elevadas temperaturas, as plantas-matriz de T. catigua não apresentam florescimento e frutificação, ocorrendo pouca brotação.

Foi observada intensa queda das folhas nas estacas nos experimentos 2 e 3 . Leonel e Rodrigues (1993) atribuíram às elevadas temperaturas a ocorrência de queda de folhas de estacas de lichieira (Litchi chinensis), que morreram, todo esse interpretado por esses autores como conseqüência da perda de água por transpiração.

Diferente dos anos de 2004 e 2005, no ano de 2006 apesar das elevadas temperaturas, houve o registro de ocorrência normal de chuvas. As observações visuais das matrizes na mata indicaram novas brotações, folhas mais verdes e ocorrência de frutificação, fato não registrado nos anos anteriores e que pode ter contribuído para as menores porcentagens de estacas mortas no experimento 3 (Tabela 2 ).

Os reguladores vegetais, utilizados em suas diferentes concentrações, não afetaram o comprimento e diâmetro das raízes em nenhum dos experimentos, e as raízes apresentaram-se curtas e finas em todos os tratamentos (Tabela 3).

As estacas enraizadas na primavera de 2004 formaram mudas, que aos 24 meses apresentavam altura média igual a $45 \mathrm{~cm}$, boa sanidade, algumas inclusive em florescimento e aptas a serem utilizadas na recomposição de matas ou em plantios comerciais. Moscheta (1995) registrou que mudas de T. catigua provenientes da germinação de sementes, aos 13 meses após a emergência, apresentavam altura variando entre 22 e $24 \mathrm{~cm}$. A produção de mudas por estacas permite maior uniformidade e menor variabilidade genética. Além disso, essas mudas tiveram menor tempo de juvenilidade, com frutificação mais precoce.

R. Árvore, Viçosa-MG, v.32, n.3, p.435-442, 2008 
Quadro 2 - Porcentagem de estacas mortas de Trichilia catigua A. Juss de acordo com os tratamentos (auxinas aplicadas em diferentes concentrações), a estação de coleta e a parte do ramo, nos experimentos 1 (primavera de 2004), 2 (verão de 2004-2005/primavera de 2005) e 3 (primavera de 2006) ${ }^{1}$

Table 2 - Percentage of dead cuttings of Trichilia catigua A. Juss according to treatments (auxins applied in different concentrations), collection season and the part of branches in the experiments: 1 (spring 2004), 2 (summer 2004/spring 2005) and 3 (spring 2006) $)^{1}$

\begin{tabular}{|c|c|c|c|}
\hline \multirow[t]{2}{*}{ Variável } & \multicolumn{3}{|c|}{ Estacas Mortas (\%) } \\
\hline & ${\text { Experimento } 1^{2}}^{2}$ & Experimento 2 & Experimento 3 \\
\hline \multicolumn{4}{|l|}{ Tratamento $\left(\mathrm{mg} \mathrm{L}^{-1}\right)$} \\
\hline AIA 1.000 & 0,00 & $32,50 \mathrm{ab}$ & - \\
\hline AIA 2.000 & 0,01 & $24,17 \quad b$ & - \\
\hline AIA 3.000 & - & $37,50 \mathrm{ab}$ & - \\
\hline ANA 1.000 & 2,09 & $34,17 \mathrm{ab}$ & $25,00 \mathrm{a}$ \\
\hline ANA 2.000 & 2,09 & $35,83 \mathrm{ab}$ & $8,33 \mathrm{a}$ \\
\hline ANA 3.000 & & $40,00 \quad \mathrm{a}$ & $20,83 \mathrm{a}$ \\
\hline AIB 1.000 & 0,0 & 38,33 a & $8,33 \mathrm{a}$ \\
\hline AIB 2.000 & 2,08 & $36,67 \mathrm{ab}$ & $8,33 \mathrm{a}$ \\
\hline AIB 3.000 & - & $36,67 \mathrm{ab}$ & $25,00 \mathrm{a}$ \\
\hline AIB 4.000 & - & - & $4,17 \mathrm{a}$ \\
\hline AIB 5.000 & - & - & $8,33 \mathrm{a}$ \\
\hline Testemunha & 3,13 & $26,66 \quad b$ & $12,50 \mathrm{a}$ \\
\hline \multicolumn{4}{|l|}{ Estação $^{3}$} \\
\hline Primavera de 2005 & - & $48,00 \mathrm{a}$ & - \\
\hline Verão de $2004 / 2005$ & - & $20,50 \mathrm{~b}$ & - \\
\hline \multicolumn{4}{|l|}{ Partes do ramo ${ }^{4}$} \\
\hline Apical & 1,79 & $35,17 \mathrm{a}$ & - \\
\hline Mediana & 0,89 & $33,34 \mathrm{a}$ & - \\
\hline
\end{tabular}

${ }^{1}$ Médias seguidas da mesma letra dentro de cada variável, na coluna, não diferem entre si, por regressão logística a 5\% .

${ }^{2}$ Não analisadas estatisticamente devido a valores zero.

${ }^{3}$ Variável testada somente no experimento 2.

${ }^{4}$ Variável testada nos experimentos 1 e 2.

Quadro 3 - Comprimento $(\mathrm{cm})$ e diâmetro $(\mathrm{cm})$ de raízes de Trichilia catigua A. Juss nos experimentos 1 (primavera de 2004), 2 (verão de 2004-2005/primavera de 2005) e 3 (primavera de 2006), de acordo com os tratamentos ${ }^{1}$

Table 3 - Length and diameter of Trichilia catigua A. Juss roots according to treatments (auxins applied in different concentrations) in the experiments: 1 (spring 2004), 2 (summer 2004/spring 2005) and 3 (spring 2006) ${ }^{1}$

\begin{tabular}{|c|c|c|c|c|c|c|}
\hline \multirow[t]{2}{*}{ Tratamentos } & \multicolumn{2}{|c|}{ Experimento 1} & \multicolumn{2}{|c|}{ Experimento 2} & \multicolumn{2}{|c|}{ Experimento 3} \\
\hline & Compr. & Diâm. & Compr. & Diâm. & Compr. & Diâm. \\
\hline IAA 1.000 & $0,65 \mathrm{a}$ & $0,19 \mathrm{a}$ & $3,21 \mathrm{a}$ & $0,10 \mathrm{a}$ & - & - \\
\hline IAA 2.000 & $0,96 \mathrm{a}$ & $0,19 \mathrm{a}$ & $2,77 \mathrm{a}$ & $0,11 \mathrm{a}$ & - & - \\
\hline IAA 3.000 & - & - & $1,93 \mathrm{a}$ & $0,09 \mathrm{a}$ & - & - \\
\hline NAA 1.000 & $1,17 \mathrm{a}$ & $0,22 \mathrm{a}$ & $2,43 \mathrm{a}$ & $0,11 \mathrm{a}$ & $0,50 \mathrm{a}$ & $0,07 \mathrm{a}$ \\
\hline NAA 2.000 & $1,55 \mathrm{a}$ & $0,23 \mathrm{a}$ & $2,23 \mathrm{a}$ & $0,10 \mathrm{a}$ & $1,13 \mathrm{a}$ & $0,11 \mathrm{a}$ \\
\hline NAA 3.000 & & & $2,04 \mathrm{a}$ & $0,09 \mathrm{a}$ & $1,70 \mathrm{a}$ & $0,09 \mathrm{a}$ \\
\hline IBA 1.000 & $0,99 \mathrm{a}$ & $0,20 \mathrm{a}$ & $2,59 \mathrm{a}$ & $0,11 \mathrm{a}$ & $0,90 \mathrm{a}$ & $0,07 \mathrm{a}$ \\
\hline IBA 2.000 & $1,40 \mathrm{a}$ & $0,25 \mathrm{a}$ & $2,58 \mathrm{a}$ & $0,10 \mathrm{a}$ & $1,10 \mathrm{a}$ & $0,07 \mathrm{a}$ \\
\hline IBA 3.000 & - & - & $1,54 \mathrm{a}$ & $0,10 \mathrm{a}$ & $2,33 \mathrm{a}$ & $0,08 \mathrm{a}$ \\
\hline IBA 4.000 & - & - & - & - & $1,63 \mathrm{a}$ & $0,11 \mathrm{a}$ \\
\hline IBA 5.000 & - & - & - & - & $1,65 \mathrm{a}$ & $0,10 \mathrm{a}$ \\
\hline Testemunha & $0,85 \mathrm{a}$ & $0,23 \mathrm{a}$ & $1,50 \mathrm{a}$ & $0,10 \mathrm{a}$ & $1,27 \mathrm{a}$ & $0,08 \mathrm{a}$ \\
\hline
\end{tabular}

Médias seguidas da mesma letra não diferem entre si, pelo teste de $\mathrm{F}$ a $5 \%$.

R. Árvore, Viçosa-MG, v.32, n.3, p.435-442, 2008 


\section{CONCLUSÕES}

Os resultados contribuíram para a melhoria na propagação vegetativa da espécie Trichilia catigua A. Juss, demonstrando que a melhor estação do ano para o enraizamento é a primavera. Podem-se utilizar tanto estacas da parte mediana quanto apical dos ramos, sendo o melhor enraizamento obtido com a aplicação de $5000 \mathrm{mg} \mathrm{L}^{-1}$ de AIB.

O fato de a Trichilia catigua apresentar crescimento lento e produção irregular de sementes faz da porcentagem de plantas enraizadas um resultado significativo para a sua propagação.

\section{AGRADECIMENTO}

À Coordenadoria de Aperfeiçoamento de Pessoal de Nível Superior - CAPES, pelo suporte financeiro.

\section{REFERÊNCIAS}

CARDOSO, J. C.; MING, L. C.; PEREIRA, A. M.S Influência de fitorreguladores em diferentes concentrações e substratos no enraizamento de estacas caulinares de bolsa-de-pastor. In: Congresso Brasileiro de Olericultura, 42: Congresso Latino Americano de Horticultura, 11, 2002, Uberlândia (MG). Suplemento 1. Uberlândia (MG): Universidade Federal de Uberlândia, 2002.

DUTRA, L. F.; KERSTEN, E.; FACHINELLO, J. C. Época de coleta, ácido indolbutírico e triptofano no enraizamento de estacas de pessegueiro. Scientia Agricola, Piracicaba (SP), v.59, n.2, p.327-333, 2002.

FACHINELLO, J. C.; HOFFMANN, A.; NACHTIGAL, J. C.; KERSTEN, E. Propagação vegetativa por estaquia. In: FACHINELLO, J. C.; HOFFMANN A.; NACHTIGAL J. C. (Ed.). Propagação de plantas frutíferas de clima temperado. Brasília: Embrapa Informação Tecnológica, p.69-109, 2005.

FAPESP, P. Na batida natural. Revista Pesquisa Fapesp, n.78, 2002. Disponível em: <http://www.revistapesquisa.fapesp.br/ index.php? art $=1884 \& \mathrm{bd}=1 \& \mathrm{pg}=1 \& \mathrm{lg}=>$ Acessado em: nov. 2006.
HARTMANN, H. T.; KESTER, D. E.; DAVIES JÚNIOR, F. T.; GENEVE, R. L. Plant propagation - principles and practices. 7ed. New Jersey: Prentice Hall, 2002. 880p.

KAPS, A.M.; LAMBERSON, W.R. Biostatistics for Animal Science. London: CABI Publishing, 2004. 445p.

KLEIN, R. M. Meliáceas. Flora Ilustrada Catarinense, 1984. 138p.

LEONEL, S.; RODRIGUES, J. D. Efeitos da aplicação de reguladores vegetais e do ácido bórico, em estacas de lichieira (Litchi chinensis SONN.). Scientia Agrária, Curitiba (PR), v.50, n.1, p.33-39, 1993.

MENDES, F. R.; CARLINI, E. A. Brazilian plants as possible adaptogens: An ethnopharmacological survey of books edited in Brazil. Journal of Ethnopharmacology, Irlanda, v.109, p.493-500, 2007.

MINDÊLLO NETO, U. R.; TORRES, A. N. L.; HIRANO, E. Enraizamento de estacas lenhosas de pessegueiro cv. Marfim em diferentes concentrações de ácido indolbutírico. -

Scientia Agrária, Curitiba (PR), v.5, n.1-2, p.55-59, 2004.

MOSCHETA, I. S. Morfologia e desenvolvimento dos frutos, sementes e plântulas de Cabralea canjerana (VELL.) MART., Guarea kunthiana A. Juss. e Trichiia catigua A. Juss. (meliaceae - melioideae). Rio Claro (SP), 1995. 160f. Tese (Doutorado em Ciências Biológicas/Biologia Vegetal) - Instituto de Biociências, Universidade Estadual Paulista.

OLIVEIRA, K. P.; SILVA, A. B.; SOFIAT, F. T.; FERNANDES, M. A.; MARQUES, L. C. Estudo farmacológico das cascas da catuaba vermelha (Trichilia catigua A. Juss. - Meliacea). In: VI Jornada Paulista de Plantas Medicinais, 2003, São Pedro. Estudo farmacológico das cascas da catuaba vermelha ( Trichilia catigua A. Juss. - Meliacea). São Pedro: 2003. 
OLIVEIRA, M. L.; XAVIER, A.; SANTOS, A. P.; ANDRADE, H. B. Efeito da estaquia, miniestaquia, microestaquia e micropropagação no desempenho silvicultural de clones híbridos de Eucalyptus spp. Revista Árvore, Viçosa (MG), v.30, n.4, p.503-512, 2006.

ONO, E. O.; RODRIGUES, J. D.; PINHO, S.Z. Interações entre auxinas e ácido bórico, no enraizamento de estacas caulinares de Coffea arabica L. cv. Mundo Novo. Scientia Agrícola, Piracicaba (SP), v.49, n.1, p.23-27, 1992.

PAES, E. D. G. B.; RIBAS, K. C. Z.; BIASI, L. A.; KOEHLER, H. S. Enraizamento de estacas de kiwizeiro (Actinidia deliciosa Lang et Ferguson cv. Bruno) nas quatro estações do ano. Scientia Agrária, Curitiba (PR), v.4, n.1-2, p.69-76, 2003.

PASTORE, J. A. Meliaceae. In: WANDERLEY, M. D. G. L.; SHEPHERD G. J.; GIULIETTI A. M.; MELHEM T. S. (Ed.). Flora Fanerogâmica do Estado de São Paulo. São Paulo: Rima, v.3, 2003.
SANTANA, D.G.; RANAL, M.A. Análise estatística. In: FERREIRA, A.G.; BORGHETTI, F. (Ed.). Germinação - do básico ao aplicado. Porto Alegre:ArtMed, p. 197-208, 2004.

SAS INSTITUTE. SAS/STAT, user's guide version 6.12. Cary, 842 p, 1998.

VIEIRA, R. F.; SILVA, S. R. Estratégias para conservação e manejo de recursos genéticos de plantas medicinais e aromáticas. Brasília: Embrapa Recursos Genéticos e Biotecnologia/Instituto Brasileiro do Meio Ambiente e dos Recursos Naturais Renováveis (IBAMA) / Conselho Nacional de Desenvolvimento Científico e Tecnológico (CNPq), v.1, 2002. 184p.

XAVIER, A.; SANTOS, G. A. D.; OLIVEIRA, M. L. D. Enraizamento de miniestacas caulinar e foliar na propagação vegetativa de cedro-rosa ( Cedrela fissilis Vell.). Revista Árvore, Viçosa (MG), v.27, n.3, p.351-356, 2003. 